\title{
Savings resulting from coupling the PV with the space cooling system
}

\author{
Bartosz Chwieduk ${ }^{1, *}$, and Adam Szelągowski ${ }^{1}$ \\ ${ }^{1}$ Warsaw University of Technology, Institute of Heat Engineering, Division of Refrigeration \\ and Energy in Buildings, Nowowiejska St. 21/25, 00-665 Warsaw
}

\begin{abstract}
The paper presents results of analysis of possible cooperation of a photovoltaic system with the space cooling devices. The size of the photovoltaic system was determined on the basis of electricity demand of the selected single family house. The demand for the electricity use for cooling and air conditioning had not been taken into account while calculating the size of PV system. On the basis of the heat balance of the building, the demand for cooling in the following hours of a year was determined. The demand for cooling and heating is affected by the heat transfer through walls, windows, floor, roof, and air exchanged through ventilation. Also solar and internal gains were taken into account. Based on Next, a cooling unit was selected. A cooling device was selected to provide enough energy to maintain the thermal comfort of the building in summer. Taking into account parameters of the selected device, the demand for electricity was determined. Based on time and hours of operation of electrical appliances in the building, a chart of electricity demand was created. The demand for cooling was included. Calculated values of the energy demand required to power all devices in the building were compared with the energy gains from the photovoltaic system. In order to calculate the energy generated by the PV system (in following hours of a year) the isotropic model of solar irradiation was used. The input solar radiation data on horizontal surface were downloaded from the website of the Ministry of Investment and Economic Development. In the last paragraphs, savings obtained in result of using the energy generated by the PV system to drive the space cooling system were determined and conclusions from the calculations were presented.
\end{abstract}

\section{Introduction}

Recent years have shown increasing interest in low-energy buildings. A modern building should have low operating costs, low demand for primary energy and should be equipped with high efficiency installations and equipment. It should also ensure good indoor climate parameters, which in high latitude countries means supplying energy for heating during winter. Lowering energy demand for heating and hot water can be achieved by using solar collectors and heat pumps. Thermal insulation reduces heat loses, and using the buffer spaces

*Corresponding author: bartosz.chwieduk@itc.pw.edu.pl 
increases solar heat gains. Both solutions reduce demand for the heating energy during winter, but in summer it can lead to overheating which causes thermal discomfort $[2,3]$. Air conditioning and space cooling can be used to improve indoor conditions but it needs energy input for operation. In high-latitude countries, increased demand for cooling occurs in the summer when ambient air temperature and solar irradiance are high. There are some opportunities to use solar energy to power refrigeration and air conditioning equipment. Arguments for utilizing solar energy for powering cooling devices are following:

- virtually free cooling due to operating costs;

- coincident between cooling demand and solar gains;

- solar energy is freely available (especially in hot and moderate climates).

Solar cooling is a technology of utilizing solar energy for useful cooling, refrigeration and air-conditioning applications. There are two basic technical methods of utilizing solar energy for cooling. First is to convert solar energy into electricity to power electrically driven cooling devices [4, 5]. Solar energy can also be converted into heat. For these purposes different solar collectors types can be used. Heat generated by a solar collector installation can be used to power thermally driven cooling devices [6,7]. The first combination is more practical in use, especially in small scale applications. Components are easily available in the market, and the whole system is less complicated in comparison to thermally driven cooling. Vapor compression cooling driven by an electric motor is well developed technology that gives a guarantee for a long operating period.

In the case of households, the use of electrical equipment does not coincide with the solar irradiance. Electricity generated by the photovoltaic modules without storing it can only cover about $30 \%$ of the total demand [8]. Combining air-conditioning and space cooling with PV systems improves indoor conditions and can improve the use of energy generated by the PV system.

\section{Air conditioning systems used in a single family house}

Air conditioning is a form of air treatment characterized by keeping a room at a fixed level of air parameters regardless of external conditions such as: temperature, humidity, pressure and cleanliness. Air conditioning system combines the functions of: ventilation (including ensuring the purity of the air through its filtration), heating, cooling, humidifying, drying. There are also devices that only provide some of these functions, mainly cooling. The most popular direct space cooling systems are: monoblock, split, and multisplit type. In a case of the single-family house, the full-air-conditioning systems are not used usually [9]. This is mainly due to economic reasons. Most popular devices for housing are split and multisplit cooling units.

Split devices are two-part refrigeration devices. The air cooler together with a fan and control dampers are placed in one housing intended for installation inside the room (indoor unit). Whereas the compressor unit, containing the compressor, condenser and the rest of the necessary equipment, are placed in a housing (outdoor unit) intended for installation outside the building. The units are connected with each other by pipelines through which the refrigerant flows. The shape and appearance of the units may be different, depending on the place of assembly.

Multisplit devices consist of several indoor units connected to one outdoor unit. Each indoor unit has independent connections to an outdoor unit. Rooms can be cooled simultaneously and independently of each other. Each indoor unit allows individual settings, regardless of the other settings.

The use of centralized refrigeration systems is possible only in the case of mechanical ventilation. In a case of the single-family house, these are usually single-conduit installations with a constant supply air temperature. In this system, fresh air is cooled in the 
central unit and then directed to rooms by supply ducts. The second independent air duct system is removed from rooms to outside. In the case of such a system, no additional cooling systems are required in cooled rooms, which ensures high aesthetics. Such a system allows cooling all rooms in a building with a relatively simple refrigeration system (a single compressor unit located outside the building and one cooling unit placed in the ventilation unit). In addition, the use of mechanical ventilation combined with the heat recovery allows additional savings for heating in the winter [10].

\section{Micro PV systems}

PV systems with nominal power up to $40 \mathrm{kWp}$ are called micro photovoltaic installations. Such systems can be divided into two main types: on-grid and off-grid. If a PV system is not connected to the grid, then it is usually a main source of electricity in the building. Those systems are used when there is no access to electricity from the grid or it is expensive to connect building to the grid. Off-grid systems are more complicated then on-grid. Except PV modules and inverters, which are the main elements of the on-grid system, the off-grid system also includes: a charging controller and batteries [11].

The vast majority of photovoltaic systems operating in Poland are systems connected to the grid. In the simplest case, all the electricity produced by the PV system is transferred to the grid. As the legal regulations favour the use of produced energy directly in a building, most of owners of the micro PV systems use inverters, that have the ability to direct electricity to devices in the building or to the grid. The ideal solution is to consume all energy produced by PV modules. However, this is difficult to achieve, because usually the highest demand for electricity does not coincide with the highest solar gains. The cooperation of cooling devices with a photovoltaic system increases the percentage of energy used directly in the building. If the system is connected to the grid, the excess of energy does not have to be stored. At the same time, in a case of insufficient amount of energy generated by the PV modules, the households can use energy from the grid. In the case of on-grid systems, the batteries are used only when it is economically justified $[12,13]$. The building considered in the paper is a single-family house, which is connected to the grid, and the energy produced by the PV system can be consumed by households or transferred to the grid [6].

\section{Electricity demand}

Electrical energy demand was determined on a basis of energy consumption of a selected single family house with capacity and working time of the electrical equipment. A photovoltaic installation size was determined using the "best month method". The best month is that one, which gives the smallest ratio of energy demand to energy gained by the PV. In analyzed case the best month is July. Solar energy gains exceed $150 \mathrm{kWh} / \mathrm{m}^{2}$. Electricity demand, excluding cooling is about $360 \mathrm{kWh} /$ month. Firstly, the size of the PV system had been determined without taking into account the space cooling system. In this case electric energy demand for the analyzed building is approximately $5870 \mathrm{kWh} /$ year. Figure 1 shows the demand for electricity in the following hours of the selected days. 


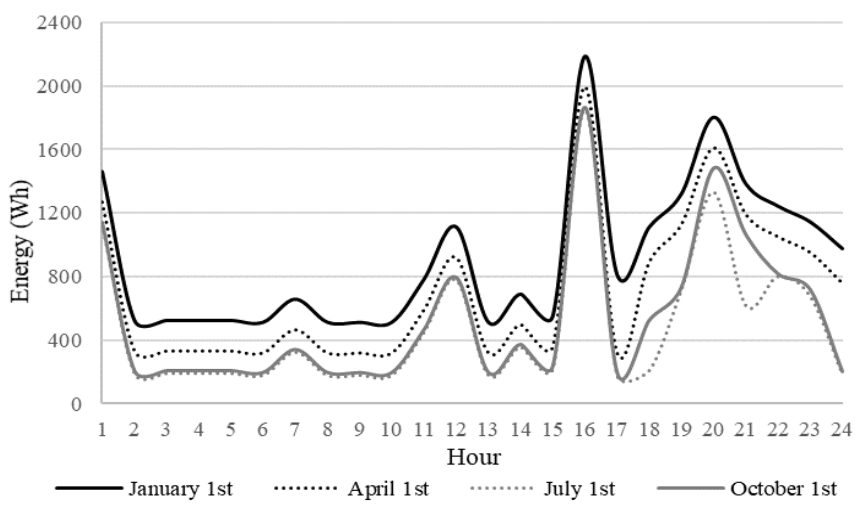

Fig. 1. Energy demand in January $1^{\text {st }}$, April $1^{\text {st }}$, July $1^{\text {st }}$ and October $1^{\text {st }}$.

Analyzed building is a detached, two-level single-family house with area of $200 \mathrm{~m}^{2}$. Transparent surfaces constitute $16 \%$ of the total surface of external walls. This house is inhabited by 4 people. The design internal temperature was set at $22^{\circ} \mathrm{C}$. The input data of ambient air temperature and solar irradiation are based on the statistical meteorological weather data for Warsaw (Poland). Solar irradiation of an envelope of the building was calculated with regard to the specific orientation and inclination of every external surface of the building. The energy balance of the building was formulated and solved giving in result the cooling loads distribution in time.

Results of calculations show that only from May to September cooling is required. During winter there is need for heating. In spring and autumn months, heat loses and gains are in balance so there is no need for heating or cooling. The cooling device works only in those days, when the heat gains are higher than the heat losses. During a single day there may happen that in a given hour the heat gains are higher than the losses, but because of thermal capacity of the building structure such small changes do not affect the heat balance.

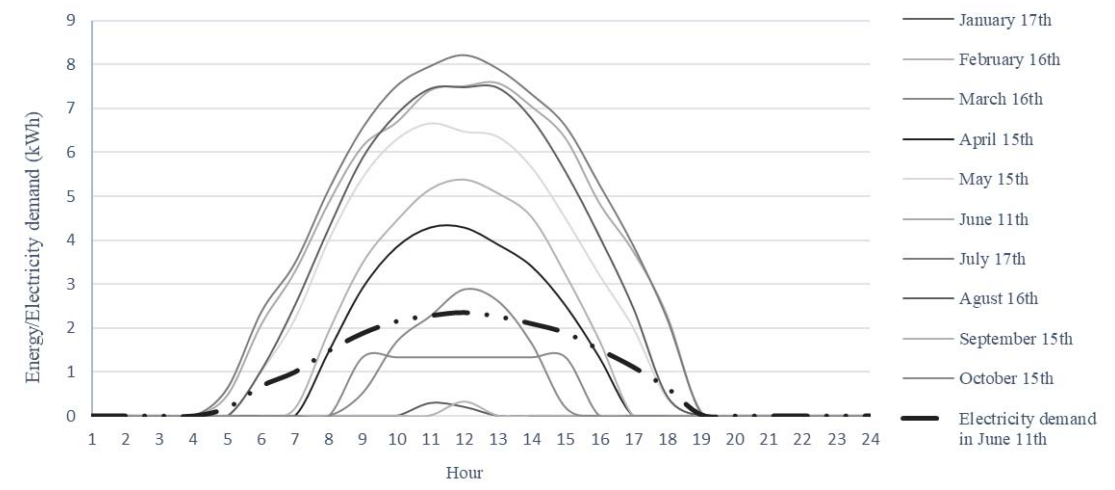

Fig. 2. Energy demand for cooling in selected days.

In Figure 2 it is visible, that in January at noon the solar and internal heat gains exceed the energy demand for heating. However, for the whole day the heat demand is higher than the heat gains and of course the cooling unit does not work. As it was mentioned operation period for the cooling system is from May to September. The electricity demand for the cooling system has been calculated with an assumption of the seasonal energy efficiency ratio (SEER) to be equal to 3.5. Most of the cooling devices available on the market meet this assumption, and even provide higher values of the SEER. Results of calculations show that the highest electricity demand for the cooling unit operation is from 11-12 hours and amounts to $2.35 \mathrm{kWh}$ in given time. Figure 3 presents the electricity demand for the cooling device. 


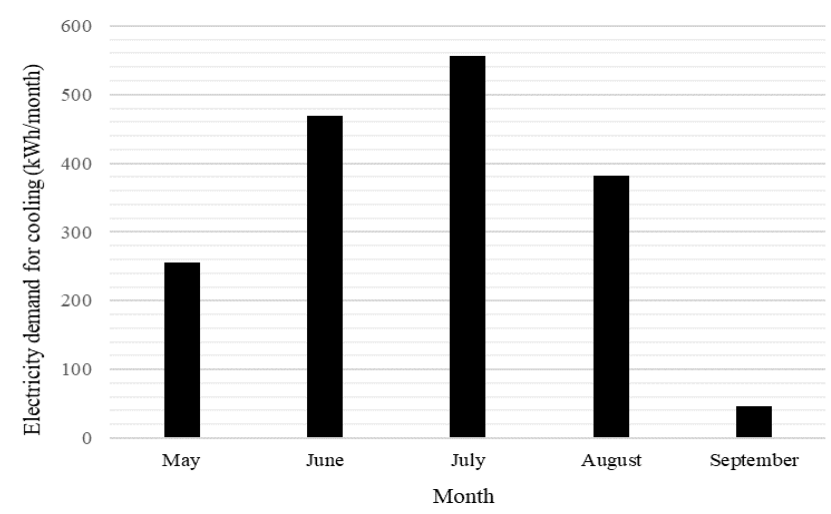

Fig. 3. Electricity demand for cooling.

The highest cooling demand occurs in July and amounts to $556 \mathrm{kWh} / \mathrm{month}$. The total demand in the period from May to September, when the thermal gains are larger than the losses is equal to $1,710 \mathrm{kWh}$.

Electricity demand for household appliances, lighting, and cooling equipment, hourly electricity demand was determined. Figure 4 shows the electricity demand for the building on selected days of the year.

The annual electricity demand is $7,580 \mathrm{kWh}$.

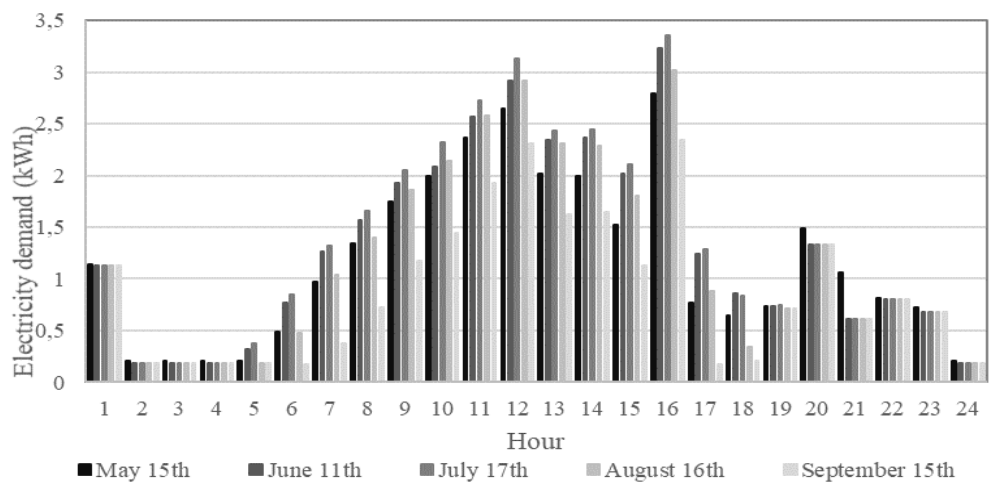

Fig.4. Energy demand on selected days of the cooling period.

\section{Determination of the size of the photovoltaic system}

The size and nominal power of the photovoltaic system was determinate with regard to electricity demand in the considered building. The calculations assume that the PV system had been installed before the decision of applying the cooling units was made. To dimension the photovoltaic system the "best" month method was used. In the best month the ratio of electricity demand to energy gains from solar irradiation is the lowest, and in that month the energy gains from PV system should be equal to the electricity demand. For the selected single family house the "best" month is July. The electricity demand in that month without taking into account the cooling needs equals $360 \mathrm{kWh}$.

The meteorological data downloaded from the website of the Ministry of Investment and Economic Development were used to calculate energy gains from the PV system. At first photovoltaic modules need to be selected. Energy gains depend on their nominal power and efficiency. The QCELLS G4.3 PV modules with power of $285 \mathrm{Wp}$ and 
efficiency of $17.1 \%$ were selected for calculations [14]. All results of calculations presented in the paper were made with an hourly time step. Taking into account the ambient air temperature which has direct influence on the efficiency and power of PV modules, the power and the energy gains of the system were determined. Figures 5 and 6 show the hourly and monthly electricity gains from the considered photovoltaic system.

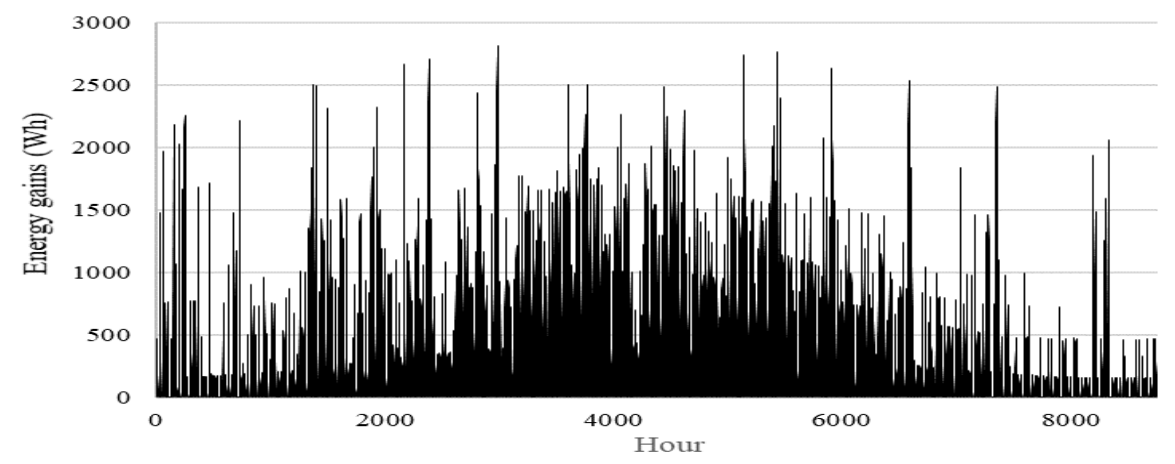

Fig. 5. Energy gains in the following hours of the year.

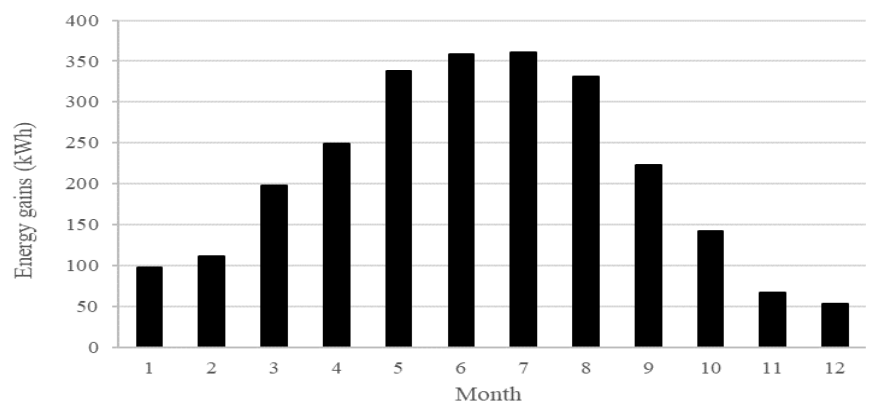

Fig. 6. Energy gain in the following months of the year.

The photovoltaic system contains 9 modules. The total power of the system is $2.6 \mathrm{kWp}$. The SKYMAX HYBRID 3kW [15] inverter which can direct the energy from the PV system to the grid or to devices in the building was selected. Total energy produced by the photovoltaic system in the first year of its operation is $2,530 \mathrm{kWh}$.

\section{Supplying the energy demand by the operating PV system}

To accurately determine the energy produced by the PV system that can drive the cooling devices, the electricity demand for all devices installed in the building was calculated. Before installing the space cooling system, the PV system was assumed to drive devices in the building such as: RTV devices, household electrical appliances or lighting. Distribution of energy demand without application of the cooling devices is presented in Figure 1 for selected days. Calculations were made with an hourly time step.

Based on the actual energy consumption, with space cooling system the year was divided into four periods with different energy demands. The total annual electricity demand, including operation of the cooling system, is equal to $7,580 \mathrm{kWh}$. Figure 7 shows the electricity demand in selected days of following months for the new case of electricity consumption. 


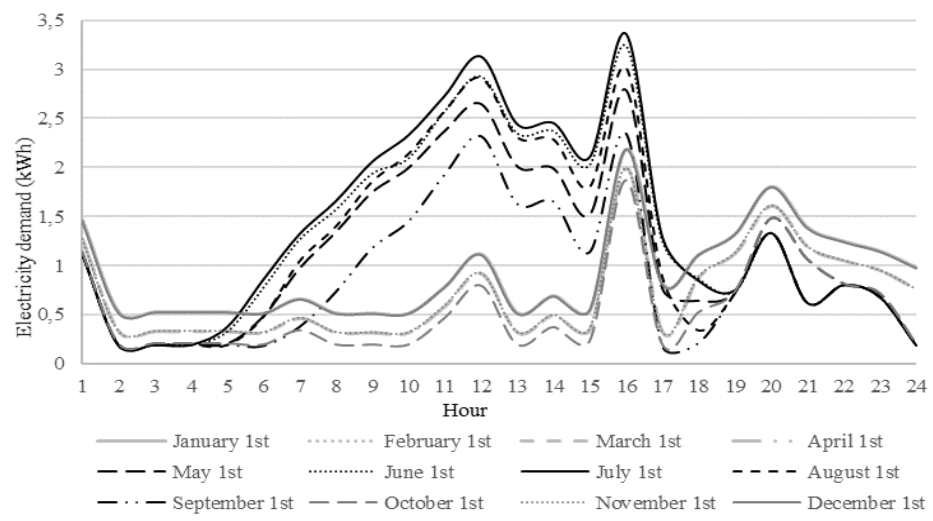

Fig. 7. Electricity demand in selected days of months.

In the case, where a cooling installation does not use the energy produced by the photovoltaic system, but only the energy from the grid, $43 \%$ of the energy produced annually by the PV system is consumed by the household. Thus, 1,440 kWh of energy produced by system is transferred to the grid. However, if the photovoltaic system is also used to produce energy to drive the cooling devices then $92 \%$ of electricity from the PV system can be used by the household members. This means that only $200 \mathrm{kWh} / \mathrm{year}$ of energy will be transferred to the grid. Figures 8-11 show the energy gains from the photovoltaic system and the electricity demand during four selected days of a year.
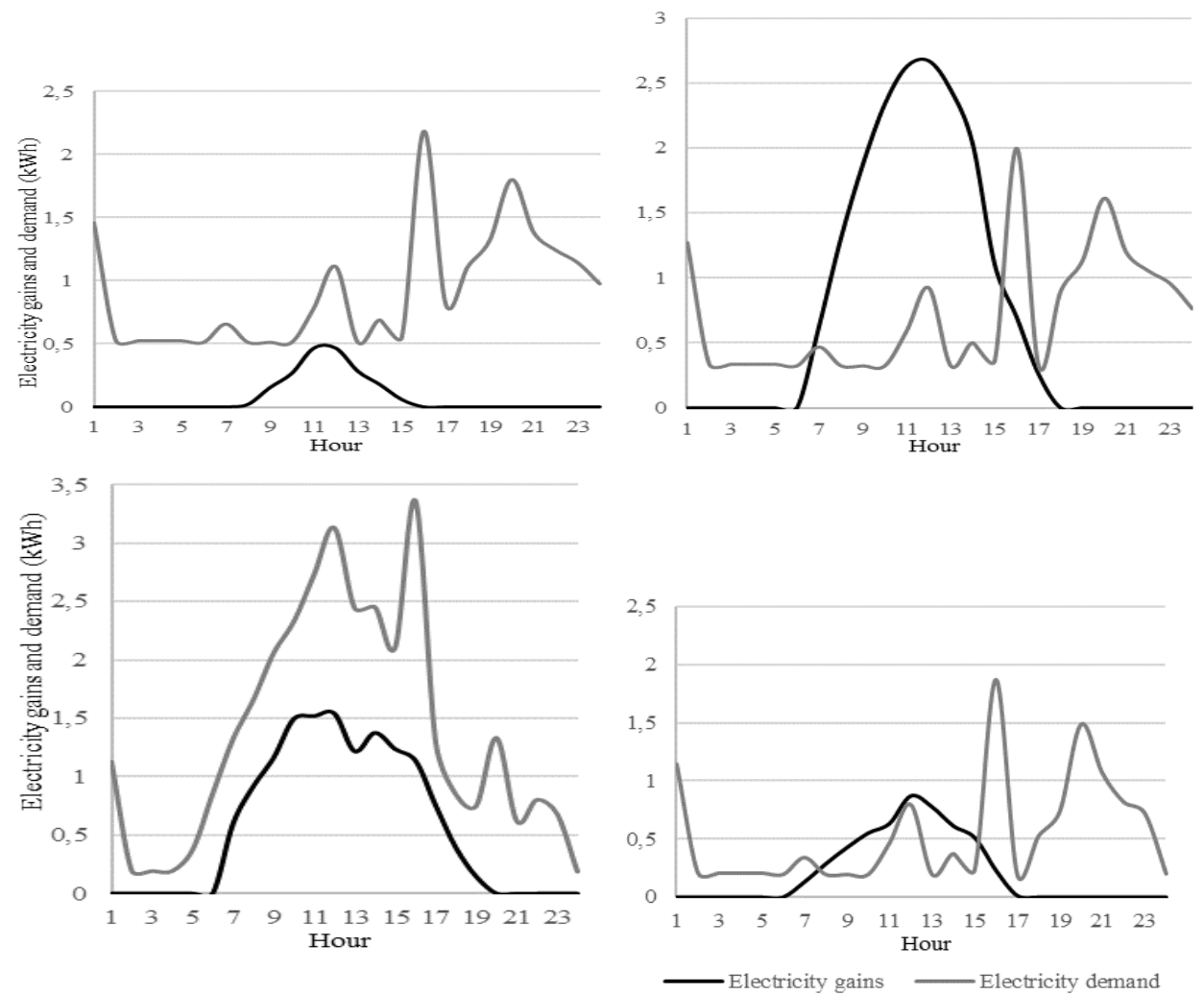

Fig. 8-11. Electricity gains and demand in January $1^{\text {st }}$, April $1^{\text {st }}$, July $1^{\text {st }}$ and October $1^{\text {st }}$. 
If the photovoltaic system drives also the cooling device, then the energy gains are higher then the electricity demand only in March, April, October and November. Figure 10 clearly shows how electricity demand for the cooling energy affects the total electricity demand. The correlation between solar gains and the demand for cooling can be noticed. In June, July and August, the demand for energy to drive the cooling unit is higher than the electricity demand for other electrical appliances in the building.

\section{Savings due to the use of the PV system}

It was assumed that the owner of the PV system can use the support mechanism for the photovoltaic micro installations. There are two types of such mechanism. In the first case, building with the PV system can be co-financing by the governmental funds. In the second case, owner of the system can have some profits because of transferring energy to the grid. Nowadays, the government subsidies have been stopped. So the calculations concern only savings from the operation of the PV system. In net metering system the grid is working as an energy storage with $80 \%$ efficiency [16]. A certain amount of the energy produced by the PV system is transferred to the grid. In the first considered case without space cooling system, it is $57 \%$ of the energy produced by the PV modules. In the second case, according to calculations only $8 \%$ of the energy generated by the photovoltaic modules is to be directed to the grid. The owner of the system can take from the grid, $80 \%$ of the energy, which had been produced by the PV system and had been sent to the grid before. The energy price in the first year of operation of the PV and cooling system is equal $0.55 \mathrm{PLN} / \mathrm{kWh}$. In the following year the price of energy grows by approximately $2.6 \%$ $[17,18]$. Figure 12 shows the energy that is produced by the PV system, transferred to the grid and used by household members in the following years of the system's operation. Lines marked with the letter "a" refer to the case where the energy produced by the PV system is not used to drive cooling device. Lines with the letter "b" refer to the case where photovoltaic system can also supply energy to cooling device.

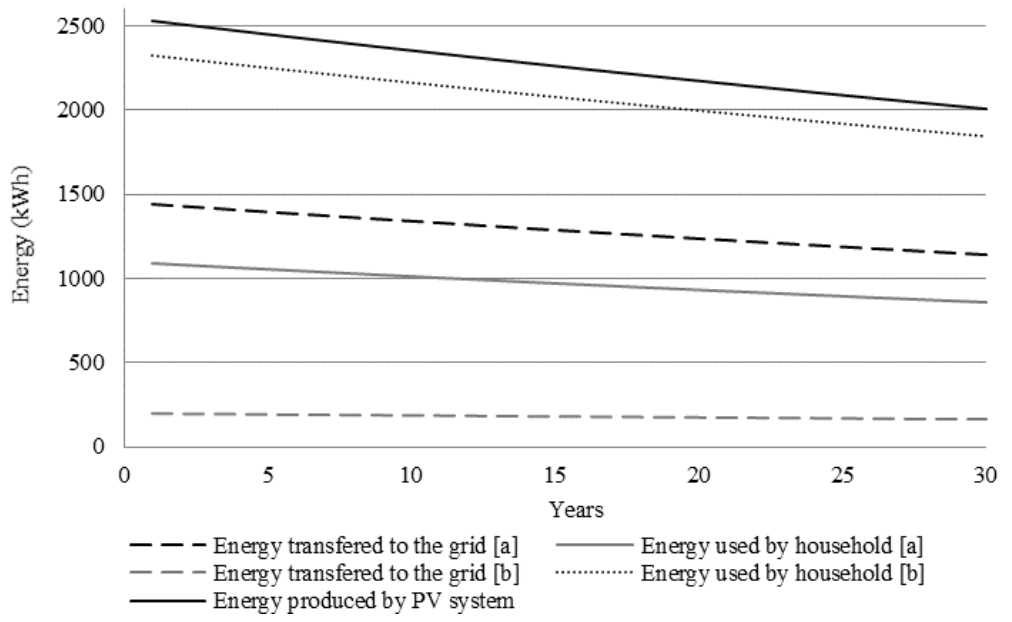

Fig. 12. Energy produced by the PV system, used by household, transferred to the grid and bought from the grid operator.

Energy gains from the PV system decrease in the following years of its operation. It is caused by the reduction of efficiency of the photovoltaic modules. Based on results of the calculations presented in Figure 12, financial savings were determined in following years of the system's operation and they are presented in Fig. 13. 


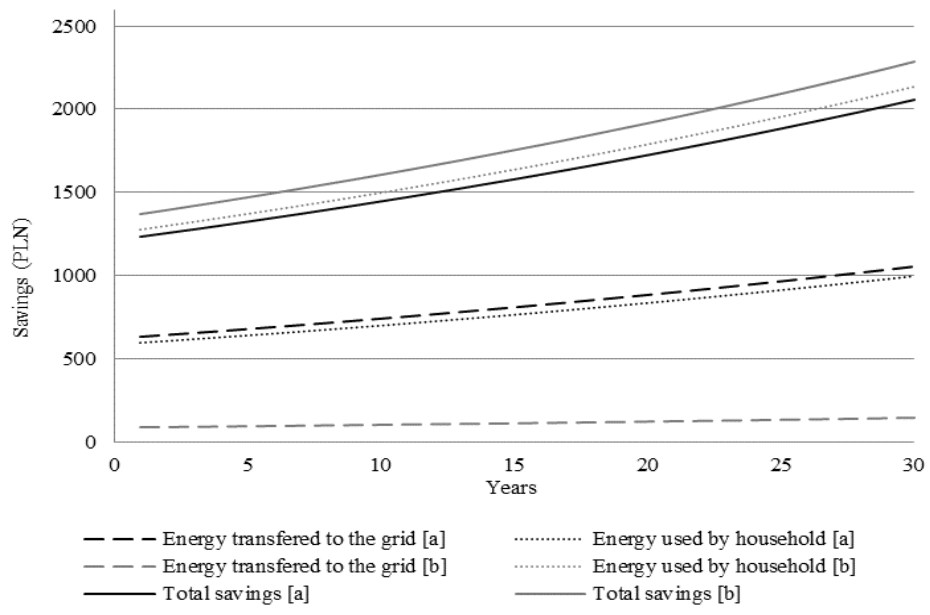

Fig. 13. Savings coming from work of the photovoltaic system.

In the case, where the energy from the photovoltaic system does not drive the cooling system and $57 \%$ of energy is transferred to the gird, the lifetime savings are equal to 24900 PLN. The rest of energy is used by household members. The savings related with using energy directly from the PV system are equal to 23,500 PLN. The lifetime of the photovoltaic system was assumed to be at level of 30 years. Total savings after this period of operating the PV system are equal to 48,400 PLN.

If the photovoltaic system also drives the cooling device, a very small part of the energy produced by the PV modules is transferred to the grid. After 30 years of operation of the system, total savings due to transferring the energy to the grid is equal to 3,500 PLN and $92 \%$ of generated electricity by the PV modules is used by the household. The savings related with this case are more than twice as high as in the first considered case. After 30 years of system's operating savings amount to 50,200 PLN.

The difference in financial saving between two considered cases is 5,300 PLN. It is about $10 \%$ of total lifetime savings.

\section{Summary and conclusions}

Using the PV system to drive the cooling device increases the amount of energy used directly from the PV generator by household members. In the second considered case, the ratio of energy transferred to the grid to total energy produced by photovoltaic system is $8 \%$. If cooling device operates independently of the PV system, most of the generated energy is transferred to the grid. Because of the current regulations with regard to the installations it is financially more benefitial to use energy directly from the PV system then to transfer it to the grid [16]. If a PV system user decides to install a cooling device, a very good solution is to use a compressor cooling device, which can cooperate with a photovoltaic system. Savings related to the operation of the PV system can increase by $10 \%$. After 30 years from the beginning of the operation the photovoltaic system and cooling device, savings amount to 53,700 PLN. It is 5,300 PLN more than in a case where two systems operate separately. Installing an space cooling system improves internal conditions. Combining it with a PV installation allows to use renewable energy to run system to meet thermal comfort in building without high operating costs. However, it is necessary to underline that in case of newly built buildings, a single family house can be constructed in Polish climate, in such a way that it does not need any cooling energy at all. 
The proposed solution particular applies in a case of old buildings in which, as a result of thermomodernization, indoor conditions during the summer deteriorated.

\section{References}

1. Typowe lata meteorologiczne $i$ statystyczne dane klimatyczne do obliczeń energetycznych budynków, www.miir.gov.pl. [access 05.03.2018]

2. M. Chwieduk, D. Chwieduk, Monografia II Kongresu Elektryki Polskiej vol. 2, 271-275 (2016)

3. D. Chwieduk, Academic Press, Elsevier (2014)

4. J. Bigorajski, JCEEA, vol. XXXIII, 63, 17-24 (2016)

5. B. Chwieduk, A. Szelągowski, Instal, 389, 50-54 (2017)

6. A. Szelągowski, A. Grzebielec, A. Rusowicz, Chłodnictwo, LI, 13-18 (2016)

7. A. Szelągowski, D. Chwieduk, Współczesne problemy termodynamiki, 457-468 (2017)

8. B. Szymański, Globenergia, (2013)

9. A. Rusowicz, A. Grzebielec, A. Szelągowski, Open Engineering, 7, 106-114 (2017)

10. A. Szelągowski, Polska Energetyka Słoneczna, 1-4, 41-46 (2015)

11. B. Chwieduk, Polska Energetyka Słoneczna I-IV, 15-20 (2015)

12. B. Chwieduk, H. Jędrzejuk, Rynek Energii 6(121), 74-80 (2015)

13. B. Chwieduk, D. Chwieduk, 12th IEA Heat Pump Conference (2017)

14. http://recost.pl/panel-modul-fotowoltaiczny-qcells-g43-285w-p-185.html (access 05.03.2018)

15. https://www.sklep.asat.pl/pl/p/Inwerter-Hybrydowy-SKYMAX-HYBRID-3kW/435 [access 05.03.2018]

16. Dz. U. 2015 poz. 478 [access 05.03.2018]

17. http://www.cenapradu.strefa.pl [access 05.03.2018]

18. http://www.idmsa.pl/231942-pge--srednioroczny-wzrost-cen-energii-elektrycznej-w-l2016-2030-to-ok-2-6-.html. [access 05.03.2018] 